\title{
Conhecimentos, práticas em Trabalho-Saúde e as abordagens da medicina social e da medicina do trabalho no Brasil: final do século XIX até os anos 1950-60
}

\author{
Francisco Antonio de Castro Lacaz ${ }^{1}$ \\ Departamento de Medicina Preventiva da Universidade Federal de São Paulo
}

\begin{abstract}
O artigo analisa a trajetória histórico-institucional das abordagens em trabalho-saúde no Brasil, do final do século XIX até os anos 1950-1960. Trata-se de estudo qualitativo, com análise documental, completada com entrevistas, que adota a tipologia de Foucault sobre as vertentes da medicina social e sua análise arqueológica. A trajetória histórico-institucional da apreensão das relações trabalho-saúde inicia-se pela medicina social urbana no século XIX, chegando à medicina da força de trabalho, quando se dá a hegemonia do setor trabalho sobre a saúde (pública) quanto à ação do Estado e ocorre a industrialização pós-1930. As diversas formas de tratar aquelas relações, têm referência no paradigma da "organização racional do trabalho", como forma de gestão do trabalho. Nessa trajetória é assinalado o papel da higiene do trabalho, da infortunística, da psicotécnica, da medicina comportamental, como importantes instrumentos de controle da força-de-trabalho, assinalando-se, por fim, a vigência da higiene industrial e sua "disputa" com a medicina do trabalho e a saúde ocupacional nos anos 1950-60. Baseado na formulação do conceito de medicina do trabalho da OMS/OIT de 1950, com o avançar do processo de industrialização brasileiro, nos anos 1950, os serviços médicos de empresa, embrióes dos serviços de medicina do trabalho, são a estratégia adotada, num momento anterior à própria exigência legal, que ocorreria somente nos anos 1970, sob o governo militar.
\end{abstract}

Palavras-chave: História, Estado, Trabalho e saúde, Medicina.

Knowledges, practices on Work and Health and the approaches on social medicine and labour medicine in Brasil: end of XIX century up to fifties-sixties of XX century

The article deals with the historic-institutional trajectory of the approaches on work and health in Brazil, from the late Nineteenth Century up to the 1960s'. It is a qualitative study, with documental analysis and interviews, in wich is adopted the approach by Foucault on social medicine, and the Archeology as methodology. The historicinstitutional trajectory in the interfaces between work and health starts by the approach of urban social medicine untill medicine of work force, and discuss replacement of the public health by the work sectors in the actions of the State, at the industrialization post-1930. It points at many ways to conceive the referred relationships influenced by the paradigm of the rational organization of work, the hegemonic way of work management. It traces back the industrial hygiene, the infortunistica, the psychotecnique and the behaviourial medicine as important tools of workforce-control, emphasising the effect of the industrial hygiene and its "dispute" with the occupational health and labor medicine in the 1950-60s. During consolidation of the brazilian industrialization process, in the fifties, the medical services in the enterprises crops up, as strategy, based in the OMS/OIT concept of labor medicine, as predecessors of the specialized sevices of labour medicine and safety, the legal work-control strategy, that was later instituted in seventies under military government by ministry of work and social welfare.

Keywords: History, State, Work and health, Medicine.

\section{Introdução}

presente artigo foi elaborado como produto de pesquisa qualitativa que constou de levantamento documental, complementado por entrevistas gravadas com acadêmicos, sindicalistas e profissionais de saúde. Adotou a arqueologia de Foucault (1987) para garimpar

1 Professor Associado I do Departamento de Medicina Preventiva da Universidade Federal de São Paulo, lotado no setor acadêmico Política, Planejamento e Gestão em Saúde. 
os enunciados, as noções, as regras, as instituições que constroem práticas e saberes sobre as relações trabalho-saúde. Resulta de estudo acadêmico que buscou analisar abordagens sobre as relações trabalho-saúde no Brasil, numa perspectiva histórico-institucional, partindo da medicina social (Foucault, 1982; Nunes, 1999; Rosen, 1994).

De conformidade com a análise de Foucault (1982), pode-se apreender três vertentes da medicina social: a medicina urbana, a polícia médica e a medicina da força-de-trabalho. Para o autor:

A medicina dos pobres, da força de trabalho, do operário não foi o primeiro alvo da medicina social, mas o último... Foi (...) no segundo terço do século XIX, que o pobre apareceu como perigo (...) na Inglaterra, durante as grandes agitações sociais do (...) século XIX, a população pobre tornou-se força política capaz de se revoltar ou (...), de participar de revoltas (Foucault, 1982, pp. 93-94).

\begin{abstract}
Assim,
...no século XIX, sobretudo na Inglaterra, [surge] uma medicina que é essencialmente um controle da saúde e do corpo das classes mais pobres para torná-las mais aptas ao trabalho e menos perigosas às classes mais ricas (Foucault, 1982, p. 97).
\end{abstract}

Como ponto de chegada para pensar o momento histórico de que trata este artigo, importa apenas assinalar que o aspecto mais relevante a ser considerado na trajetória aqui investigada é que o surto industrial desenvolvimentista dos anos 1950 concretiza a estratégia da implantação dos Serviços Médicos de Empresa (SMEs), os quais, além de atuarem no atendimento clínico-individual, também assumem papel no estudo das causas de absentismo, na seleção de pessoal e na análise de doenças e acidentes ocupacionais, visando a seleção de mão-de-obra mais hígida, o controle do absenteísmo, o rápido retorno à produção, já que “...existe um papel importante, do ponto de vista dos empresários, a ser desenvolvido por uma seção médica no interior das empresas..." (Teixeira \& Oliveira, 1978, p. 181).

A medicina do trabalho e a higiene tornam-se insuficientes para apreender as agora cada vez mais complexas relações entre trabalho-saúde havendo a necessidade de uma racionalidade científica mais abrangente consubstanciada na saúde ocupacional - melhor elaborada conceitualmente e que absorve contribuições da higiene industrial, da toxicologia, da epidemiologia e da própria saúde pública, momento em que a medicina do trabalho confunde-se, conceitualmente, com a saúde ocupacional (Mendes, 1980). Trata-se de atuação multiprofissional, calcada no sanitarista, para intervir nos locais e ambientes de trabalho sob viés positivista-quantitativo que se insinua na ânsia pelo controle dos riscos quantificados e medidos nos locais de trabalho. É o mesmo espaço e objeto da higiene industrial, mas agora sob um olhar ambientalista e especializado, conforme preconizavam as escolas de saúde pública como Harvard, Johns Hopkins e Michigan (Mendes, 1995). Assim, outros conhecimentos são integrados ao discurso médico no diálogo com a psicologia, a sociologia e a economia (Faleiros, 1992).

Sob a égide da saúde ocupacional, proliferam então os SMEs (Mendes, 1980) e empresas de grande porte, estatais e multinacionais neles investem mantendo

...serviços de assistência médica (...), independentes tanto das práticas tipicamente liberal-privadas, quanto do setor estatal, desenvolvido por uma secção médica no interior das empresas (Teixeira \& Oliveira, 1978, p. 181).

Controle fabril e seleção instituem-se nos SMEs, tendo como sustentação teóricoprática a saúde ocupacional-medicina do trabalho, de conformidade com a formulação, 
datada de 1950, do comitê misto de experts patrocinado pela Organização Internacional do Trabalho e pela Organização Mundial de Saúde (Mendes, 1980).

Frise-se que o discurso técnico articulado às relações de poder para disciplinar o trabalho institucionaliza-se legalmente no Brasil somente nos anos 1970, sob a ditadura militar, quando o Ministério do Trabalho e Previdência Social, através de portarias, regulamenta os Serviços Especializados em Engenharia de Segurança e Medicina do Trabalho (Seesmet) em 1972 e 1975 (Lacaz, 1996).

A ação do Estado na saúde dos trabalhadores apreende a saúde como razão instrumental ou como fator de produção, o que vai caracterizar sua atuação desde o Ministério do Trabalho, Indústria e Comércio (MTIC) até o Ministério do Trabalho e Previdência Social, com total omissão do "setor" saúde (Lacaz, 1996).

Aqui é mister salientar como registro da história recente a importante conquista do movimento social brasileiro através da Reforma Sanitária, o que contribuiu para que nos anos 1980 tal realidade se modificasse. Melhor explicando: a saúde é assumida como direito, na perspectiva da cidadania, e o Estado, através do Sistema Único de Saúde (SUS), deverá assumir atribuições no campo Saúde do Trabalhador, agora considerada atividade de saúde pública, disputando a hegemonia do "setor" trabalho e da saúde ocupacional-medicina do trabalho (Lacaz, 1996).

\section{A trajetória das abordagens}

Por tratar-se de estudo que aborda a temática em período datado, propõe-se a análise de uma continuidade histórica, mesmo que não linear, para compreender sua configuração na atualidade, visando entender o campo Saúde do Trabalhador (Lacaz, 2007).

Para se pensar a realidade do Brasil, será considerado o que aponta Foucault (1982) e pode-se então afirmar que o olhar da medicina (social) sobre a vida da sociedade brasileira na terceira década do século XIX dá-se pela vertente da medicina urbana, cuja intervenção no ambiente ocorre

...não (...) [sobre] o corpo produtor... A medicina é social por detectar na cidade as causas de um estado patológico da população e formular um projeto de normalização da sociedade como condição para produzir o estado positivo da saúde (Machado, Loureiro, Luz \& Murici, 1978, p. 351).

Como a industrialização amadurece apenas no século XX, inexiste, na origem da medicina social no Brasil, "... a condição de possibilidade da medicina social 'enquanto' olhar (...) no trabalhador, corpo que adoece e morre" (Machado et al., 1978, pp. 352-353).

Percebe-se, pois, que não é identificada uma patologia relacionada diretamente com o trabalho - mesmo em locais de trabalho insalubres como matadouros, fábricas de velas de sebo e sabões -, tendo importância apenas as emanações para o ambiente circundante, conforme apontavam teses defendidas na Faculdade de Medicina do Rio de Janeiro em meados do século XIX (Mendes, 1980, 1995).

Somente no final do século XIX é que a

...saúde pública tentou, (...), superar (...) ameaças sanitárias à força de trabalho, (...) buscou afirmar-se como ...técnica (...) no combate às doenças epidêmicas em que ocuparia também a função pedagógica de normatizar grupos sociais refratários às boas regras higiênicas (Costa, 1986, pp. 14-15). 
Sob a égide da economia agrário-exportadora, a prioridade era o saneamento de portos e ferrovias, das vias de transporte e o escoamento da produção agrícola. E, ao lado das campanhas sanitárias, ocorre o envolvimento do próprio médico Oswaldo Cruz (o pai das campanhas) nas frentes de trabalho para a construção da estrada de ferro Madeira-Mamoré no ano de 1910, onde a preocupação com as doenças infecciosas relacionadas ao trabalho, como a malária e o amarelão, tornavam incapazes e matavam milhares de trabalhadores (Mendes, 1995).

Para tais empreitadas colabora o conhecimento trazido da bacteriologia e da higiene, havendo, então,

...a idéia de que para cada doença existe um agente etiológico... [com] deslocamento do eixo "social" - vago, (...), incômodo para uma sociedade capitalista emergente - para o eixo das "causas específicas" [a] impulsionar (...) os estudos e a práxis da Patologia do Trabalho (Mendes, 1995, p. 11).

Nos anos 1920, com a Reforma Carlos Chagas, a hygiene do trabalho incorpora-se ao âmbito da Saude Publica através do Departamento Nacional de Saude Publica (DNSP), órgão vinculado ao Ministério da Justiça e Negócios Interiores.

No "deslocamento" da medicina social para a fábrica, a hygiene do trabalho detecta na seleção dos trabalhadores qualidades e requisitos psico-fisiológicos dos quais resulta um padrão ótimo e, na seleção do operário, será escolhido aquele que mais se aproxime do "modelo" estabelecido para cada profissão (Barreto, 1929).

É o que defende o autor:

A Doutrina da interferência, em muitos accidentes, de uma verdadeira susceptibilidade individual, hoje assentada em base solida, firmada (...) pelas verificações conduzidas pelo Industrial Fatigue Research Board, da Inglaterra. Greenwood (...), em 1919, Newbold (...) mostraram por methodos estatisticos que, como diferem os individuos em altura, em peso, na força muscular... tambem divergem na predisposição aos accidentes (Barreto, 1929, p. 245).

A partir de 1930 a atribuição das ações de hygiene do trabalho passa a ser do recémcriado Ministério do Trabalho, Indústria e Comércio (MTIC), fruto da Revolução de 30, através da Inspetoria de Hygiene e Segurança do Trabalho do Departamento Nacional do Trabalho, DNT (Mendes, 1995).

A incorporação do discurso da hygiene do trabalho pelo MTIC dá-se mediante outra divisão de atribuições dos órgãos de Estado, alijando a Saude Publica. Tal fato alia-se ao caráter do Estado pós-1930, que assume características não-liberais ao buscar a tutela dos trabalhadores.

O Estado confrontara-se com uma classe operária tornada sujeito social, através de entidades representativas influenciadas pelo anarquismo que interferem na vida nacional, como ocorreu nas grandes greves do final da década de 1910 (Simão, 1966). As greves reivindicam a regulação das relações de trabalho para barrar a superexploração. Visam normas para duração da jornada, idade mínima de trabalho, repouso remunerado, controle do trabalho noturno, do trabalho da mulher e denunciam as péssimas condições e ambientes das fábricas e oficinas (Dean, 1980).

Conforme aponta Gomes (1994), a radicalização das mobilizações paredistas e sua derrocada em conseqüência de forte repressão e posterior cooptação, tarefa esta executada pelo MTIC, conforma uma classe operária dócil e corporativista. 
É na virada dos anos 1920-1930, pela hygiene, que a ação do Estado, via MTIC, incide no espaço da fábrica e, nesse momento, a organização científica do trabalho é a forma hegemônica de gestão da força-de-trabalho (Taylor, 1913/1982).

Aliada da hygiene, a bacteriologia subsidiará a abordagem das relações trabalho, saúde e doença, relacionando-as à exposição a agentes nocivos, objetos de duas disciplinas: a medicina legal - voltada aos nexos entre doenças e riscos "inerentes" às ocupações, faz pensar nas doenças e acidentes como infortúnios, objeto da infortunística - e a hygiene, que trata das causas e da prevenção dos efeitos, a qual, quando aplicada à fábrica, constitui-se na hygiene do trabalho (Mendes, 1995).

A abordagem da hygiene e da medicina legal desloca a estratégia da medicina social/saude publica baseada no controle sanitário de caráter público, coletivo, ambientalurbano com ênfase nas doenças pestilenciais. Prevalece a hygiene do trabalho voltada para o indivíduo, devido ao interesse centrado na seleção da força-de-trabalho, para controlar, com o apoio da infortunísitica, o "factor humano" causador de acidentes e de doenças desestabilizadores do ordenamento instaurado pela organização científica do trabalho (Lacaz, 1996).

Tal discurso tem por base doutrina importada dos Estados Unidos e da Inglaterra e esposada por Barreto (1929), médico-sanitarista que foi o introdutor do ensino da hygiene do trabalho no Brasil, após freqüentar curso de saúde pública nos Estados Unidos em 1925. Ele exerceu o cargo de secretário geral do DNSP nos anos 20 (Mendes, 1995).

E, num repto aos empresários, ele assinala que as variabilidades devem ser detectadas pelo olhar rigoroso, vigilante e positivo de uma certa "Saude Publica" prescritiva, dirigida à fábrica, para além da "hygiene industrial". Conforme aponta Barreto (1929, p. 246):

....avulta a (...) realização (...) de medida de capital importancia hoje em assumptos de saude publica - em campo, portanto, mais vasto ainda que o da hygiene industrial - a dos exames de saude periodicos.

A sua realisação, pelos serviços de medicina preventiva nas fábricas, cuja instituição (...) é incomprehensivel não esteja a correr parallelamente ao desenvolvimento industrial, é tarefa indispensavel e complementar dos exames previos (...)... O defeito (...) despercebido (...), porque não se traduzia ainda por signaes nitidos, virá se desvendar aos (...) exames realisados periodicamente. (...) graças a provas de laboratorio de valor seguro, a aç̧ão malefica de muitos toxicos, empregados nas industrias, pode-se (...) presentir em tempo de evitar (...) damno...

Impunha-se agir dentro das fábricas. Dada a limitada capacidade de intervenção do Estado, tais ações deveriam ser desenvolvidas pelas empresas nos "centros de saude districtaes". E, para Barreto (1929, p. 247):

[a] ...prevenção dos accidentes, cabe (...) á organização medica industrial, com feição de serviço de medicina preventiva... é possivel estende-lo, facilmente, ás pequenas industrias pelo systema dos centros de saude districtaes, mantidos pelas proprias fabricas...

Discurso impregnado pela hygiene, pela medicina legal informada pela infortunística, pela saúde pública normativa dirigida ao indivíduo e à fábrica, que naturalizam a ocorrência de agravos à saúde no trabalho, aliando a fatalidade da propensão ao acidente no trabalho com sua inevitável nocividade (Lacaz, 1996).

Também assume importância no discurso higienista, sob o taylorismo, a fadiga, o que irá preocupar os "higyenistas industriaes" de formação norte-americana. E, mesmo que no Brasil a realidade de trabalho fosse diversa, tratava-se não mais da fadiga relacionada à 
extensão das jornadas, ou ao esforço físico, mas àquela relacionada ao próprio taylorismofordismo. A hygiene industrial, cientificamente aplicada, dará conta dela apesar da teimosa presença da propensão ao erro e ao descuido. Mais uma vez, é esclarecedor buscar socorro nas palavras de Barreto (1929, p. 249):

O problema da fadiga é (...) dos que mais preocupam os hygienistas industriaes. (...) a introducção (...) de machinismos reduz a solicitação do esforço muscular, (...) [mas] surgem outras causas de fadiga... [n]o trabalho industrial moderno. A velocidade (...) na produção exige attenção incessante... Acaba cansando (...) a monotonia de uma mesma operação (...) As posições fixas, forçadas (...), os ruidos (...) são outras (...) causas provadas de fadiga, que a hygiene evita com a mudança de trabalho para os operarios (...), pelo estudo racional dos movimentos uteis para cada operação (...) estabelecimento cuidadoso das pausas, cujo numero e duração, (...) vão se estebelecendo mercê de investigações (...) com rigoroso determinismo scientifico, são (...) recursos a restringirem a fadiga industrial e a (...) desattenção (...), o descuido no trabalho, factor de (...) relevancia na ocorrencia dos accidentes.

Numa rede de relações articulam-se o discurso científico da prevenção (dito) e o da seleção (não dito) que vislumbra

...a organização perfeita: seres humanos ajustados às exigências (...) dos postos de trabalho... dentro do esquema taylorista, a melhora da atividade humana no trabalho pode conseguir-se (...) procurando a seleção dos trabalhadores e formando-os adequadamente... (Vidal \& Brunet, 1984, pp. 171-172).

Critérios "científicos" agem na seleção dos trabalhadores na medida em que os locais de trabalho eram um espaço degradado

...em que se viciam todos os meios de vida, facilitam-se (...) as ocasiões de agressão e nocividade naturais, aumentadas ainda pela rotina, (...) e má educação do proletariado, mal alimentado, mal vestido,(...), viciado pelo álcool e fumo $\left(\right.$ Peixoto $^{2}, 1922$, citado por Bertolli-Filho, 1993, p. 38).

Discurso higienista no qual as mazelas da população mestiça, degenerada e ociosa devem ser abolidas das fábricas.

A incessante busca de estratégias "científicas" para o recrutamento ideal persiste. Datam da primeira década do século XX os estudos europeus calcados nas ciências do comportamento, com posterior influência no Brasil, a respeito da propensão ao acidente relacionada a características psicológicas. A ferramenta desse conhecimento é a psicotécnica que, aliada ao taylorismo, avaliará as capacidades individuais, escolhendo o trabalhador melhor adaptado para cada posto de trabalho: "A seleção de pessoal (...) permitiu aos tayloristas ter a organização perfeita: seres humanos ajustados às exigências minuciosamente descritas dos postos de trabalho" (Vidal \& Brunet, 1984, p. 171). A psicotécnica apreenderá “....as regularidades (...) que regem o comportamento de seus 'objetos naturais' (...) as leis que governam ditos objetos naturais” (Vidal \& Brunet, 1984, p. 174).

O taylorismo, que impregnava conhecimentos e práticas, exerceria também influências sobre o empresariado paulista, que criou em 1931 o Instituto de Desenvolvimento da Organização Racional do Trabalho (Idort) com assessoria da Escola Livre de Sociologia e Política de São Paulo. O Idort patrocinaria estudos sobre o trabalho, visando o aumento da produtividade, enfocando a organização do trabalho e a aplicação de princípios, métodos, regras emprestadas do taylorismo (Santos, 1975).

2 A. Peixoto, médico, é co-autor, do livro Accidentes do Trabalho, veículo da idéia de infortúnio que impregna a Higiene e Medicina do Trabalho. Fala "da infelicidade, (...), da desgraça, falta de sorte (...) do risco inerente ao trabalho". 
Nos anos 1930-1940, o Idort,

ao qual se filiava a maioria dos psicólogos do trabalho (...), desenvolveu programa de divulgação dos "métodos racionais" de trabalho e administração. Propunha (...) implantação de serviços e (...) de novas atitudes face ao "fator humano" no trabalho (Santos, 1975, p. 102).

No contexto político e sócio-econômico pós-Revolução de 1930, a industrialização domina a acumulação do capital em que convivem maneiras diversas de produzir: grandes fábricas e oficinas de fundo de quintal (Dean, 1980).

Sob o getulismo, o setor trabalho é o espaço da medicina social "provedora", semelhante à proposta da policia médica (Foucault, 1982). Conforme assinala Gomes (1994, p. 226):

No Brasil, antes de 30, pouco se fizera na (...) medicina social. (...) de 1930 a 1937, vasto programa se implantara (...). Foram criados seguros contra invalidez, doença, morte, acidentes de trabalho e o seguro maternidade, (...) o Brasil incorporava a (...) medicina social que se desenvolvera na Europa... $\mathrm{O}$ trabalhador passava a ser assistido pelo Estado, que se preocupava (...) com sua saúde física, (...) sua adaptação psíquica ao trabalho realizado... Daí a relação entre a política de saúde e as modernas técnicas de seleção e orientação profissionais...

No (...) interesse do progresso do país, deviam se vincular (...) as legislações social e sanitária, (...) [para] (...) construir trabalhadores fortes e sãos, com capacidade produtiva ampliada. O papel da medicina social (...) concretizado pela ação dos Institutos de Previdência e Assistência Social, consistia (...) em preservar, recuperar e aumentar a capacidade de produzir...

O locus privilegiado de desenvolvimento dessa linha populista do governo Vargas é o MTIC, instância que no Dia do Trabalho de 1943 instaura a Consolidação das Leis do Trabalho (CLT), uma regulamentação voltada ao interior das fábricas.

E, sob o discurso pelo aumento da capacidade produtiva, a CLT

...estabelece apenas as condições mínimas e isto num momento em que a indústria começa a preocupar-se com a produtividade. Sem tais condições é impossível aumentar a produtividade do trabalho (Faleiros, 1992, p. 122).

Tratava-se de dar concretude à empreitada que associa prevenção e seleção de mãode-obra na busca da produtividade, quando os operários industriais são reconhecidos como contingente que precisa ser disciplinado por técnicas e conhecimentos, conforme o taylorismo (Bertolli-Filho, 1993).

O que foi insinuado academicamente nos anos 1920-1930, ganha projeção e concretiza-se nos anos 1940 pela prática fabril da "medicina do comportamento", que incluía a psicotécnica. Através da seleção e do acompanhamento médico periódico dos trabalhadores, a medicina lança mão de um arsenal de conhecimentos para a correção da ação mental dos operários (Bertolli-Filho, 1993).

A força e o poder do discurso disciplinador e culpabilizador que articula a medicina do comportamento com os interesses dominantes são marcantes. Nos anos 1940, por exemplo, é publicado o livro Asssitencia psychotechnica: estudo technico do homem no trabalho, pelo médico Raul Rocha (Bertolli-Filho, 1993). 
Tal discurso é, porém, esvaziado pela realidade do mercado de trabalho e, posteriormente, a "abordagem psicotécnica" assume outros contornos, dada a postura empresarial, conforme aponta Bertolli-Filho (1993, p. 43):

...foram poucas as empresas que se dispuseram a arcar com os custos (...) das orientações prescritas pelos "psicólogos", inclusive porque a abundância de mão-de-obra viabilizava a pronta substituição dos funcionários inadaptados.

De qualquer forma, a sugestão de estudo e acompanhamento "científico" dos trabalhadores ganhou resposta (...), frutificando ainda na década de 40 em entidades como o SENAI, (...) e o SESI.

O Serviço Nacional de Aprendizagem Industrial (Senai), criado em 1942, inicialmente para apoiar ferrovias federais e privadas na capacitação e seleção de recursos humanos, amplia seu escopo e, conforme aponta Carelli (1975, p. 103):

...começa, (...), um amplo programa de utilização da psicologia nos serviços de orientação e seleção (...) de pessoal para os trabalhos da indústria... Os estudos e aplicações da psicologia concentram-se, (...) no uso de testes e mensurações (...) para a predição de comportamento...

No final dos anos 1940 a segurança e as condições de trabalho na indústria são bastante precárias. Nessa época, conforme afirma Faleiros (1992, p. 142):

...Blomfield, assistente-chefe da Divisão de Higiene Industrial do Serviço de Saúde Pública dos Estados Unidos, realizou uma enquete no Brasil junto a 24 indústrias (...), no quadro da cooperação entre [os] países. Os estabelecimentos inspecionados compreendem indústrias (...) têxteis e indústrias modernas de produtos químicos, metalúrgicos e petroleiros...

Em relação aos serviços de saúde (...), Blomfield destaca que em 97\% (...) existe uma sala para socorros de urgência, mas o médico de tempo integral só existe em 39\% das indústrias... [e] todas já adotam a prática dos exames de admissão da aptidão do trabalhador em $100 \%$ dos casos.

O discurso da prevenção assumido pelo patronato é exangue, convivendo com a hipertrofia da seleção e, pelo levantamento de Blomfield, fica claro que: “...os patrões adotam a prática do controle profissional da aptidão ou inaptidão dos trabalhadores em vez da prática do controle das condições de trabalho" (Faleiros, 1992, p. 142).

Apesar da "abertura" pós-Estado Novo, em 1946, um grupo de empresários preocupados com os avanços das lutas operárias cria com

o objetivo de obter maior produtividade e de freiar o movimento de adesão aos comunistas... instituição de reabilitação e prevenção para operários (...) o [SESI] (...) [que] oferece serviços de educação, médicos, odontológicos... Implanta um instituto específico de reabilitação de acidentados (Faleiros, 1992, p. 142).

No pós-guerra, tornam-se mais complexas as relações trabalho-saúde-doença, dado o avanço tecnológico dos processos produtivos, o que se faz acompanhar de um rearranjo na divisão internacional do trabalho, conforme Feijóo (1995).

Tendo descurado da formação e da qualificação da mão-de-obra, o patronato aposta como estratégia, de novo, na seleção rigorosa dos candidatos ao emprego, tendo como importante aliado um "novo higienismo" e seus instrumentos. Nos anos 1950, intensificam-se os contatos com experts norte-americanos higienistas industriais e, em São Paulo, cria-se o Serviço de Higiene Industrial (SHI) do Serviço Social da Indústria (Sesi), o qual conta com 
médicos e engenheiros sanitaristas formados, entre o final dos 1940 e o início dos 1950, nas escolas de saúde pública norteamericanas, a partir da cooperação técnico-científica estabelecida pelo governo brasileiro com as fundações Rockfeller e Ford, iniciada na década de 1910 (Lacaz, 1996).

No novo ciclo industrial inaugurado nos anos 1950, as indústrias de bens de consumo duráveis predominam e, sem trocadilhos, o "carro-chefe" desse empreendimento foram as multinacionais automobilísticas. Agora os SHI assumem importante papel, desenvolvendo metodologia para elaboração de inquéritos de higiene industrial, adotados em São Paulo e Rio de Janeiro, mediante abordagem epidemiológica aliada à higiene, com avaliação de ambientes, condições de trabalho e exames médicos.

É importante observar que nos anos 1950 a higiene industrial desloca o protagonismo do médico nos serviços de empresa. Agora os novos "baluartes" são o engenheiro, o químico. O papel limitado dos médicos quanto à prevenção é criticado pela hipertrofia da atividade assistencial com poucos resultados e ônus econômico para a produção. Conforme Taylor e Gondim (1955, pp. 583-584):

...concentrar atenção sôbre problemas médicos individuais tem efeito adverso sôbre a filosofia de prevenção (...), não em relação ao enfêrmo e incapacitado (...), porém ao ambiente (...) responsável pelas doenças. E o estudo do ambiente não é um problema médico, porém, uma análise de profundo sentido, econômico e de engenharia, das alterações necessárias, a fim de prevenir riscos (...) de acidentes e enfermidades e (...) proteger o interêsse do fabricante em produzir a custo razoável.

Os referidos autores eram engenheiros ligados ao SHI de Niterói. O primeiro deles, norte-americano, foi consultor do Instituto de Assuntos Inter-Americanos (IAIA); o segundo, brasileiro com formação nos Estados Unidos, era funcionário, à época, do Serviço Especial de Saúde Pública (Sesp). O Sesp, assessorado pelo IAIA, celebrara, em 1953, convênio com a Secretaria da Saúde e Assistência de Niterói para a criação do SHI naquela Secretaria, o qual passou, em 1954, a realizar inquéritos de higiene industrial em indústrias do Estado do Rio de Janeiro, cujos resultados foram motivo de outra publicação (Gondim \& Latgé, 1959). O mesmo já vinha fazendo o SHI do Sesi de São Paulo, por influência de Blomfield, que, como foi dito, estivera no Brasil em 1949, tendo publicado, em 1950, o livro Problemas de higiene industrial no Brasil (Faleiros, 1992).

Data também de meados dos anos 1950 a realização de inquéritos sobre doenças do trabalho: dermatoses, pneumoconioses, intoxicações por chumbo, estas bastante freqüentes na emergente indústria automobilística.

Em entrevista concedida ao autor, o médico Bernardo Bedrikow, professor decano de medicina do trabalho na Faculdade de Ciências Médicas da Santa Casa de São Paulo até os anos 1980, formado em saúde pública e higiene do trabalho em Harvard nos anos 1950 e um dos fundadores, em meados de 1950, do ambulatório de doenças profissionais do Sesi de São Paulo, refere que na casuística do ambulatório, após as dermatoses ocupacionais aparecia, como agravo,

[e]m segundo lugar a intoxicação por chumbo (...) Por causa da indústria automobilística. Foi período do crescimento desordenado da indústria automobilística. Aquele negócio heróico de fazer 100 caminhões por dia. E cada caminhão, cada ônibus levava 10 a $12 \mathrm{~kg}$ de chumbo (...) derretido no maçarico. Isto representou esta verdadeira epidemia: 1.000 casos de intoxicação em um curto espaço de tempo. Tudo bem documentado!

Se o Sesi foi um importante espaço de formulação patronal no desenvolvimento da abordagem das doenças profissionais, ao concretizar-se a industrialização, no final dos anos 
1950, serão os SMEs - embriões dos futuros Serviços de Medicina do Trabalho (SMTs) - a base da estratégia adotada, o que se consubstanciará apenas nos anos 1970, quando o Estado delega às empresas a tutela da saúde dos trabalhadores, ao tornar legal a implantação dos SMTs através de portarias emanadas do Ministério do Trabalho e Previdência Social (Lacaz, 1996).

Apenas a título de informação, a continuidade do estudo dessa trajetória vai iluminar o caminho para entender como a saúde pública, a saúde coletiva e a medicina social latinoamericana sustentaram novos conhecimentos e práticas em trabalho-saúde para intervir nas realidades de trabalho que se constituiram nos anos seguintes, bem como nas suas conseqüências para a saúde dos trabalhadores (Lacaz, 2007).

\section{Referências}

Barreto, J. B. (1929). Prevenção dos accidentes de trabalho. Archivos de Hygiene, 2, 243-264.

Bertolli-Filho, C. (1993). Medicina e trabalho: as "ciências do comportamento" na década de 40. Revista de História, 127/128, 37-51.

Careli, A. (1975). O Serviço de Ensino e Seleção Profissional da Estrada de Ferro Sorocabana e seu papel na introdução e desenvolvimento da psicologia aplicada ao trabalho no Brasil. Boletim de Psicologia, 26 (69), 111-114.

Costa, N. R. (1986). Lutas urbanas e controle sanitário: origens das politicas de saúde no Brasil. Petrópolis: Vozes.

Dean, W. (1980). A industrialização de São Paulo (1880-1945). São Paulo: Difel.

Faleiros, V. (1992). O trabalho da política: saúde e segurança dos trabalhadores. São Paulo: Cortez.

Feijóo, J. C. V. (1995). O Estado neoliberal e o caso mexicano. In A. C. Laurell (Org.), Estado e politicas sociais no neoliberalismo (pp. 11-52). São Paulo: Cortez.

Foucault, M. (1982). O nascimento da medicina social. In R. Machado (Org.), Microfísica do poder (pp. 79-88). Rio de Janeiro: Graal.

Foucault, M. (1987). A arqueologia do saber. Rio de Janeiro: Forense Universitária.

Gomes, A. C. (1994). A invenção do trabalhismo. Rio de Janeiro: Relume Dumará.

Gondim, P. M. \& Latgé, M. (1959). Problemas de higiene industrial no Estado do Rio de Janeiro. Revista do Serviço Especial de Saúde Pública, 10 (2), 565-606.

Lacaz, F. A. C. (1996). Saúde do trabalhador: um estudo sobre as formações discursivas da academia, dos serviços e do movimento sindical. Tese de Doutorado, Faculdade de Ciências Médicas, Unicamp, Campinas.

Lacaz, F. A. C. (2007). O campo saúde do trabalhador: resgatando conhecimentos e práticas sobre as relações trabalho-saúde. Cadernos de Saúde Pública, 23 (4), 757-766.

Machado, R., Loureiro, A., Luz, R. \& Muricy, K. (1978). D(an)ação da norma: a medicina social e constituição da psiquiatria no Brasil. Rio de Janeiro: Graal.

Mendes, R. (Org.). (1980). Medicina do trabalho. Doenças profissionais. Rio de Janeiro: Sarvier.

Mendes, R. (Org.). (1995). Patologia do trabalho. Rio de Janeiro: Atheneu.

Nunes, E. D. (1999). Sobre a sociologia da saúde. Origens e desenvolvimento. São Paulo: Hucitec.

Rosen, G. (1994). Uma história da saúde pública. São Paulo: Hucitec.

Santos, O. B. (1975). Psicologia aplicada e psicotécnica em São Paulo. Boletim de Psicologia, 26 (69), 101-104. 
Simão, A. (1966). Sindicato e Estado. São Paulo: Dominus.

Taylor, F. W. (1913/1982). Princípios de administração científica. São Paulo: Atlas.

Taylor, G. J. \& Gondim, P. M. (1955). Desenvolvimentos recentes da higiene industrial no Brasil. Revista do Serviço Especial de Saúde Pública, 7 (2), 583-593.

Teixeira, S. M. F. \& Oliveira, J. A. (1978). Medicina de grupo: a medicina e a fábrica. In R. Guimarães (Org.), Saúde e medicina no Brasil: contribuição para um debate (pp. 181-206). Rio de Janeiro: Graal.

Vidal, E. Q. \& Brunet, M. M. (1984). Los paradigmas de la psicologia industrial-organizacional: perspectiva historica. Revista de Psicologia Geral y Aplicada, 39 (1), 167-190.

\section{Endereço para correspondência}

franlacaz@medprev.epm.br

Recebido em: 23/04/2007

Revisado em: 02/08/2007

Aprovado em: 05/08/2007 